\title{
Blockchain in the social sphere of Smart Cities
}

\author{
Vladimir Plotnikov ${ }^{1,2, *}$, Lyudmila Vardomatskaya ${ }^{3}$, and Valentina Kuznetsova ${ }^{4}$ \\ ${ }^{1}$ Saint-Petersburg State University of Economics, 21 Sadovaya str., 191023, St. Petersburg, Russia \\ ${ }^{2}$ South West State University, 94, 50 let Oktiabria str., 305040, Kursk, Russia \\ ${ }^{3}$ Rostov State Medical University, 119, Suvorov str., 344022, Rostov-on-Don, Russia \\ ${ }^{4}$ Herzen University, 48, Moika emb., 191186 St. Petersburg, Russia
}

\begin{abstract}
The development of smart cities is based on the use of new technologies. One of these promising technologies is Blockchain. The use of Blockchain gives great opportunities for solving a complex of problems related to: ensuring energy efficiency in buildings, the introduction of sustainable energy technologies for megacities, the formation of ecofriendly settlements, etc. The article analyzes the possibilities of using Blockchain technology in the social sphere of the city. The analysis is carried out on the example of health and pharmaceuticals. The study was carried out in the framework of the institutional approach and the concept of economic opportunities. The objectives of the study were: to identify specific areas of use of Blockchain technology in the pharmaceutical and health care industries; to evaluate the role of this technology in ensuring compliance with medical standards, transparency and safety of drugs at all stages of their development, promotion and use; to determine the possibilities of technology in identifying more effective and high-quality treatment methods, their implementation in practical health care. The article presents the structure of the areas of pharmaceuticals and health care, where the Blockchain is used. The strategies are offered to reduce labour and energy costs for processing medical information, accelerating the creation of new treatment technologies and the creation of medicines, their implementation in practical health care..
\end{abstract}

\section{Introduction}

Humanity is evolving along the path of urbanization. This is confirmed by the following facts [1]:

- Now, more than half of the world's people live in cities.

- By 2030, all developing regions, including Asia and Africa, will have more people living in urban than rural areas.

- Cities account for some 70 percent of global GDP.

Concentration of population and economic activity in cities leads to the smell of environmental problems. Sustainable urban development in these conditions becomes a priority problem. Ecological well-being can be achieved not only by "external" measures related to the implementation of the environmental policy, but also by changing the

\footnotetext{
*Corresponding author: plotnikov_2000@mail.ru
} 
traditional processes of life in the cities. The growing concentration of population and economic activity in cities requires the development of new approaches to their management.

Today, new technologies are required for use in cities. It is necessary to ensure sustainable development and functioning of cities [2-7, 12]. This is a serious challenge for the 21 st century. One answer to this challenge is the formation of smart cities. The Smart City Concept integrates information and communication networks, digital technologies, and various intellectual devices [8]. The goal of this Concept is to optimize the efficiency of city operations and services, and connection of citizens to new services [9].

The development of new technologies is a defining moment for the formation of smart cities. One of these new technologies is Blockchain. The goal of the article is to analyze the possibilities of using Blockchain technology in the social sphere of the city. The analysis is carried out on the example of health and pharmaceuticals. In this article, the authors continue research, the results of which were included in an earlier publication [9].

\section{The blockchain technology and its properties}

Stimulating the development of new information technologies is an important priority of economic policy. The State Administration of Russia understands this and takes measures to develop institutional regulation. In May 2017, Russia adopted the Strategy for the Development of the Information Society in the Russian Federation for 2017-2030 (Decree of the President of the Russian Federation), and in July 2017, the State Program "Digital Economy of the Russian Federation" (Order of the Government of the Russian Federation). These documents determine the actions of the authorities and local self-government in the application of information and communication technologies.

These technologies are considered as an essential element of national infrastructure. To implement these documents, sectoral projects of social and economic development are being developed today. Among these projects is the Healthcare Project, for the development of which it is planned to allocate 200-300 billion rubles annually (approximately 2.5-4.5 billion USD).

One of the breakthrough technologies of the digital economy, which can lead to fundamental changes in various industries and increase their efficiency, is Blockchain technology. The introduction of Blockchain in the socially oriented sphere will allow providing a digital society with all the necessary conditions and technological mechanisms, eliminating intermediaries, and ensuring the authenticity of operations. This makes it possible to form digital images (avatars) on the Blockchain platform, to record all transactions.

In European countries, there is a huge interest in Blockchain technologies. Today, Blockchain technology is one of the most promising areas of the digital industry. There is a forecast that in 2027 up to $10 \%$ of world GDP will be stored in the Blockchain (World Bank data). The spread of blockchain technology is enormous. Studies conducted by the "Grand View Research" and "Transparency Market Research" companies showed that if the global blockchain market in 2015 was $\$ 509$ million, by 2024 it will grow to $\$ 20$ billion.

In his book on "Business innovation through the blockchain" Vincenzo Morabito defines Blockchain as a technology - a distributed, decentralized, cipher-protected database, a public depository of information, in which every perfect transaction is recorded and becomes known to all network members [10].

And Don Tapscott and Alex Tapscott in their work "Blockchain Revolution" complement this definition and highlight the seven principles of building Blockchain Economics [11]: 
- Network integrity. Integrity is encoded in each step of the process and is distributed among all participants, and does not belong to one subject.

- Load distribution. Energy costs are distributed throughout the network. None of the participants can turn off the system.

- Value as an incentive. The system aligns the incentives of all stakeholders.

- Security. Security measures are built into the network. They provide confidentiality and authenticity.

- Privacy. People control their data.

- Security rights. The rights of owners are transparent and fixed.

- Involvement. The economy works better when it works for everyone.

The main feature of Blockchain is that the data entered into the system once cannot be changed by anyone, the data is repeatedly duplicated. Information is stored on a distributed network created and maintained by all participants. These data are always available, they cannot be faked, the databases are resistant to hacker attacks. Blockchain can solve problems in real time, openly and transparently.

\section{Prospects for using blockchain in healthcare}

Currently in Russia a lot of attention is paid to health care. This is one of the priorities in the social sphere. In health care, it is planned to modernize information support in the near future through the creation and operation of Federal information systems of medical and pharmaceutical organizations. Work is being carried out at the level of the Ministry of Health to identify specific areas for the introduction of digital information technologies, including Blockchain technology.

Research in this area is being actively pursued. There are different points of view about the use of Blockchain in health care. So, D. Kulish, the founder and managing director of drugdevelopment.ru (Center for Entrepreneurship and Innovation Skoltech), believes that all medicine should not be transferred to the Blockchain technology, but it is more expedient to use Blockchain technology in certain areas (see details at: http://blockchainhouse.media):

- Storage of personal genomic information that will allow it to be safely stored, studied and even sold.

- Record data from monitors that the patient carries with him for diagnostic purposes (for example, a fitness tracker). This data has great diagnostic and analytical value. Access to this information for other users is denied.

- Diagnostics. During the examination, the patient accumulates certain diagnostic data that can either be lost by the medical institution (if they are left for storage in the hospital), or are distorted by the patient (if they are transferred for storage to the patient). If this data is recorded in the Blockchain, then neither the first nor the second will be impossible.

This view has good reasons. In Russia, the main part of medical documents is drawn up on paper. There is no unified national register of information about patients, which would include all information about their visits to medical organizations, not only in public, but also in private ones. The patient's medical history is also made out mostly by hand, and information from it can easily be made public, which negatively affects the need to preserve medical confidentiality. In the case of medical error, including fatal, data on the patient's health status, as well as treatment technology can be easily adjusted.

The use of the Blockchain technology means the rejection of paper carriers in favor of digital, preservation of patient information confidentiality, reduction of the number of mediators between the doctor and the patient, creation of medical products for each patient 
individually, etc. The digital case history will allow the doctor to trace all stages of the patient's treatment. It will be impossible to make any unauthorized changes in order to adjust the patient's health status indicators.

Other authors believe that the Blockchain technology in healthcare has more opportunities (see details at: https://bloomchain.ru): compilation of chronicles of medical developments and prescriptions in the field of medicine; display of real competence and activity of the doctor; report on the quantity and quality of medicines prescribed to the patient; obtaining information about the complete register of diseases, if you enter categories for patients; the use of telemedicine, which will make a real revolution in health care.

The generalization of various Russian studies related to the implementation of Blockchain in health care allowed the authors to determine the following list of positive effects:

- High-speed access to the necessary information from any region of the country (this is especially important for Russia, where long distances and communication are poorly developed. In addition, vast territories are non-urbanized. And urban agglomerations are usually monocentric).

- Fast data processing.

- Operational exchange of experience in treating diseases, which will lead to an increase in the qualifications of doctors.

- Display of the real work of the doctor. There is a possibility of effective remote control over his actions.

- Report on prescription pharmaceuticals. This is important for budget planning and for preparing sectoral and regional balances.

- Simplify the assessment of the quality of medical care, which will positively affect the efficiency of the work of medical personnel.

- Translation of the document circulation of healthcare organizations onto Blockchain. This will increase the speed of data processing, provide transparency and the impossibility of losing, damaging or falsifying documents, since the block created once cannot be changed, it cannot be removed from the network.

- It will be possible for each patient to store a copy of the personal medical data base, as well as access it using a unified protocol.

- Timely distribution of laws, orders, etc., relevant medical news.

- Ensuring confidentiality of case histories.

- A potential employer, an insurance company, and other interested parties will be able to access the professional data of the health worker and confirm what competencies they have.

- Reducing the burden on the doctor. Electronic case management, in contrast to paper carriers, requires less time and effort.

- Go to digital contracts and paperless transactions, which will significantly reduce the cost of medical care.

- Ensure transparency of financial flows of health facilities, reduce the number of subjects of financial relations.

- Create a register of medical information about patients across the country by disease groups, which will facilitate and accelerate health research; to identify more effective and high-quality methods of treatment, to introduce them into practical health care; speed up and reduce the cost of developing new drugs. 


\section{Opportunities for using blockchain in pharmaceuticals}

The use of Blockchain in the pharmaceutical industry has broad prospects. Some pharmaceutical companies (Amgen, Sanofi, etc.) propose to apply the blockchain technology to document tests of new drugs. This will create a database of each new drug, as well as those who have expressed their desire to participate in such tests. A universal database of information storage will allow us to document, save and update all data, the effectiveness of the tested drugs, take into account their side effects, which will speed up the process of creating new drugs [10].

Another implementation direction for Blockchain is connected with the labeling of drugs with a special chip for protection against fakes. Such a Blockchain chip will be able to distinguish a real cure from a fake or counterfeit one. For this you need a special electronic device. The Blockchain technology will be used at all stages of the movement of the drug from the manufacturer to the patient.

In the Blockchain document, if the supplier of drugs or the pharmacy decided to make changes to the record, then a new document will be automatically created, as a continuation of the main one, but already with corrections. A growing list of ordered entries forms Blockchain (chain of events). Each block contains a timestamp and a link to the previous block. However, it cannot be moved by changing the chronological order. It is transparent, objective and cannot be changed. It is important to emphasize that the task of effective control is solved without a centralized regulator, which could change and transfer data at its own discretion. This makes the process cheaper and the information more reliable.

The positive effects of the Blokchain technology implementation in pharmaceuticals are the next [10]:

- It is possible to translate all document circulation of pharmaceutical organizations into a Blokchain.

- Blokchain make ensure that information cannot be falsified.

- A single register of electronic recipes will be created.

- Savings will be achieved by not taking into account prescription drugs on paper.

- Ensure transparency of financial flows in healthcare, especially in its public sector.

- Reduce the state budget spending on quality control of medicines. These costs will decrease in absolute terms due to the use of Blockchain.

\section{Conclusion}

Blockchain is a promising technology. The use of this technology can improve the quality of management in many areas. Analysis of the Blockchain's application potential in the social sphere (using the example of Healthcare and Pharmaceutics) showed that this technology can make many processes cheaper, faster, and more transparent. Therefore, the authors recommend speeding up the implementation of practical measures for using Blockchain technologies.

Solving the problems of introducing new technologies requires large investments. This is the interest of industry organizations. In Russia, pharmaceutical companies are mostly private. They have the necessary resources for technological modernization, or can attract them in the form of bank loans. Health care in Russia is mainly state-owned. Therefore, medical institutions do not have sufficient resources to implement Blockchain (this is not provided for in their budgets). Therefore, it is necessary to implement special state programs in this area.

Medical care of the population is a task solved in Russia at the regional and municipal levels, it is advisable to lay the corresponding expenses in the budgets at these levels of government. The largest financial resources are concentrated in cities, especially in 
megacities (Moscow, St. Petersburg, Yekaterinburg, Rostov-on-Don, etc.), a significant number of people live there too. Therefore, the implementation projects for Blockchain in Healthcare and Pharmaceuticals should first of all be carried out in these cities. Opportunities for this are available in the framework of projects to modernize Russian cities, turning them into "smart cities".

\section{Acknowledgements}

The paper is an output of the science project of the government task of Ministry of education and science of the Russian Federation \# 26.3546.2017/PCH "Development fundamentals of analysis and prediction of structural and dynamic parameters of the regional economy are based on the integration of the Russian and world experience of management of territorial development and modern scientific doctrines".

\section{References}

1. J. Beall, S. Fox, Cities and Development (Routledge Taylor \& Francis Group, 2009)

2. S. Campbell, Journal of the American Planning Association 62(3), 296-312 (1996)

3. Y.V. Vertakova, G.L. Zvyagintsev, T.N. Babich, Y.S. Polozhentseva, IOP Conference Series: Earth and Environmental Science 87(4), 042026 (2017) DOI: 10.1088/17551315/87/4/042026

4. Y.P. Soboleva, A.V. Polyanin, O.V. Leonova, O.A. Korgina, A.V. Merkulov, Espacios 39(33), 31 (2018)

5. E. Tkachenko, S. Bodrunov, Proceedings of the European Conference on Knowledge Management ECKM3, 964-973 (2014)

6. Y. Vertakova, V. Plotnikov, Economic Annals-XXI 166(7-8), 4-10 (2017) DOI: 10.21003/ea.V166-01

7. V.I. Lutin, E.N. Desyatirikova, O.V. Kuripta, N.V. Akamsina, V.E. Mager, 2018 IEEE Conference of Russian Young Researchers in Electrical and Electronic Engineering (EIConRus), 1113-1116 (2018) DOI: 10.1109/EIConRus.2018.8317285

8. M. Peris-Ortiz, D.R. Bennett, D.P.-B. Yábar, Sustainable Smart Cities: Creating Spaces for Technological, Social and Business Development (Springer, 2016)

9. V. Plotnikov, V. Kuznetsova, MATEC Web of Conferences 193, 02029 (2018) DOI: 10.1051/matecconf/201819302029

10. V. Morabito, Business innovation through blockchain: The $B_{3}$ perspective (Springer, 2017)

11. D. Tapscott, A. Tapscott, Blockchain Revolution (Portfolio/Penguin, New York, 2016)

12. A. Lanko, N. Vatin, A. Kaklauskas, MATEC Web of Conferences 170 (2018) doi:10.1051/matecconf/201817003032 